\title{
Does Legal Epistemology Rest on a Mistake? \\ On Fetishism, Two-Tier System Design, and Conscientious Fact-Finding
}

\author{
David Enoch, Talia Fisher, and Levi Spectre*
}

Legal epistemology seems to be exploding. More and more philosophers seem to be taking an interest in the theory of evidence law, and to bring along with them to legal theory the freshest news from the abstract study of epistemology ${ }^{1}$. This is understandable, of course: The law in general, and evidence law in particular, seems to be employing the same natural-language terms epistemologists are (or are at least supposed to be) interested in ("knew or should have known", "reasonable doubt", "evidence", "presumption" (of innocence), and so on) ${ }^{2}$. Perhaps for this reason, an interest in legal epistemology has been there long before the current explosion ${ }^{3}$. Still, the extent of attention paid by epistemologists to legal epistemology seems unprecedented (whether this interest is reciprocated by legal theorists, let alone legal practitioners, is of course another matter).

In this paper we want to argue that a large part of this project is based on a mistake, roughly analogous to the mistake involved in thinking of studies of intelligence as relevant to the understanding of military intelligence. With qualifications shortly to emerge, epistemology is not, we think, intrinsically and directly relevant to normative evidence law theory, at least, that is, as long as the relevant perspective is that of designing the evidence law regime. When it comes to the conscientious fact-finder, things may be - we're not sure about this - importantly different.

Now, many things go by the name "legal epistemology", and it's not as if we think all are based on a mistake. It makes perfect sense to ask how different standards of proof are best understood, or - in

\footnotetext{
${ }^{*}$ For comments on earlier versions we thank Matt Kotzen and Sarah Moss. Earlier versions of this paper were given as talks at the Social (Distance) Epistemology Virtual Event Series, in June 2020, and at the "Emerging Trends in Criminal Justice: Writers' Workshop" at Osgoode Hall Law School. We thank the participants of both occasions.

${ }^{1}$ Bolinger (2018), Blome-Tillman (2017), Gardiner (2019b, 2021), Hoskins, Z., \& Robson, J. (2021), Moss (2018a, 2018b, 2021b), Pardo (2010, 2018), Pritchard (2018), Smith (2017, 2018, 2021a, 2021b), Stein (2018). For a comprehensive bibliography see Gardiner (2019a) and for critical surveys of central epistemological views see Gardiner (2018) and Ross (2020). To an extent, we have been a part of this trend: See our (2012) But our engagement in legal epistemology is not, we're sure you will be surprised to hear, guilty of the mistake of which we are about to accuse many others.

Some of those engaging our 2012 account ((Moss 2021b), (Blome-Tillman 2015), (Pardo 2018), and (Smith 2018)) have (mis)represented us as putting forward an epistemic account - an epistemic Sensitivity based account - and thereby as guilty of the very mistake we warn against already in that original paper, a warning we expand on here. Seeing that we emphasized in that paper that we don't think the epistemic story (as opposed to the incentive-based one) justifies normative conclusions in evidence law theory, we are not, nor have we been, guilty of that mistake. In comments on an earlier draft, Moss explains that her use of "epistemic theories" of statistical evidence is much wider, and so that thus understood, her characterization of our view is not false. Even if this is so, though, it is still misleading.

2 Though see Allen (2021) for the claim that the term "knowledge" - assumed to be legally central by many doing legal epistemology - is actually suspiciously absent from large bodies of legal doctrine and text.

${ }^{3}$ See, for instance, Cohen (1977), Thomson (1986), and Laudan (2006).
} 
jury systems - how juries are (to be) instructed. It makes perfect sense to ask about the consequences in the real world of employing different evidence law regimes. It makes sense to wonder whether people have procedural rights that extend to how the law should assess evidence, and what follows if they do. (This is not meant as an exhaustive list.) What we focus on in this paper - and what we say is deeply mistaken - is the attempt, roughly, to do legal epistemology just by doing epistemology, or to treat epistemological considerations (say, about the nature of knowledge or evidence) as decisive, or even just intrinsically relevant, to normative questions in evidence law theory. There is a lot that our criticism allows room for: Obviously, other subprojects of legal epistemology (as with the examples above) are not even challenged by our criticisms; nor will we challenge other legal uses of epistemic concepts, external to the theory of evidence law (as when the substantive law puts things in terms of "knew or should have known") ${ }^{4}$; also, our discussion allows for the productiveness of thinking about epistemology in doing legal epistemology - but with a twist. Sometimes, perhaps noticing that intuitions in legal epistemology originate from broader ones in epistemology may be the beginning of a debunking explanation of those intuitions as applied to evidence law theory - because the law, in a slogan, should not care about epistemology 5 .

In section 1 we briefly comment on the relation between truth and evidence law. In section 2 we argue against the willingness to give up any of the substantive goods the law is supposed to deliver just in order to secure for our legal findings the epistemic status of knowledge. Then, in section 3 , we extend this claim from knowledge to any other purely epistemic good. By the end of section 3 , then, we take ourselves to have clarified and then established the claim that the law shouldn't care about epistemology. In section 4 we concede ways in which this result gives rise to some intuitive discomfort, which we then address in section 5. There, we suggest a distinction - theoretically inspired by Rawls in "Two Concepts of Rules" (1955), and more practically inspired by the phenomenology of judging (as

\footnotetext{
${ }^{4}$ It is an interesting question - one we do not discuss here at all - whether such references to epistemic concepts in substantive law should be understood at face value, and whether philosophical accounts of them can be assumed to apply to their legal uses as well. At least with regarding to some, one of us has argued that the answer is "no". (See the last section of Enoch (2013)). But notice that the knowledge-fetishism thought, of which much more below, does not directly apply to such legal uses of epistemic concepts.

${ }^{5}$ Our own initial contribution to legal epistemology (2012) was partly in this spirit: We emphasized the similarity between intuitions about statistical evidence in law and elsewhere, and offered the beginning of an epistemological explanation that covers all of these instances. But we then insisted that this cannot vindicate the intuitive objectionability of legally relying on statistical evidence without a further, practical (and not epistemological) story. And we put forward such a story as well (which we briefly return to below).

For the corollary claim - that epistemologists have relatively little to learn from the law - see Backes (2020).

In general, the looser the connections - in either direction - between epistemology and the law, the less plausible are epistemic accounts of evidence law, and in particular of statistical evidence, and so - even more specifically - epistemic critiques of our own story about statistical evidence. For such epistemic critiques, see Blome-Tillmann (2015) and Moss (2021b).
} 
brought to our attention in a conversation with Aharon Barak) - between the considerations that govern the design of a legal system, and those that guide the specific conscientious fact-finder.

\section{Evidence Law and Truth}

Clearly, evidence law is to a considerable extent concerned with truth. At least in part, evidence law is geared towards fact-finding, towards reaching the true answers to the relevant factual questions ${ }^{6}$. And just as clearly, truth legally matters, as well it should.

Accounts as to why it is that truth matters - and should therefore be an aim of evidence law - may be intrinsic, or instrumental, or - most plausibly - both. ${ }^{7}$ Instrumentally, it seems clear that for the law to do whatever good it is supposed to do (and we say more on this below), it can't get things too wrong too often. Perhaps, for instance, the criminal law is supposed to fairly express the community's condemnation of certain forms of conduct, or perhaps it is supposed to deter undesirable, harmful conduct. Perhaps the law of torts is supposed to distribute the risks of harm fairly, or to incentivize socially efficient behavior, or to guard against one agent making objectionable use of another. If the law's findings are entirely disconnected from the relevant truths (who did what under what circumstances with what mental state, etc.), then the law will not be able to fairly express the community's condemnation ${ }^{8}$ (because it will "condemn" many cases in which nothing is condemnable, and fail to condemn many condemnable cases), or to deter undesirable conduct ${ }^{9}$ (because it will also deter many cases of desirable conduct and fail to deter many cases of undesirable conduct), and so on for any other good the law may deliver. Sure, the legal system is bound to make factual mistakes. And making such mistakes from time to time is consistent with the law's successfully delivering whatever goods it is supposed to deliver (though arguably, each such mistake has its costs). Indeed, the law may be able to deliver some significant goods despite even considerable rates of systematic mistakes. Still, without at least some significant correlation between the law's factual findings and the relevant truths, it is hard to see how the law can achieve anything worth achieving. So it's not surprising if evidence law is at least partly about truth.

But you may think that such instrumental stories - about how truth may facilitate the legal system

6 "Nearly all of the Anglo-American writers from Gilbert to Cross have shared essentially the same basic assumptions about the nature and ends of adjudication and about what is involved in proving facts in this context. There is undoubtedly a dominant underlying theory of evidence in adjudication, in which the central notions are truth, reason, and justice under the law.", Twining $(1984,272)$; "The reasonably accurate determination of disputed factual issues is...the pivotal task to be performed at trial.", Nance $(1988,236)$.

Even if these claims are too strong, they still demonstrate the unequivocal role truth plays in evidence law.

7 "In the final analysis, it must also be said that truth has intrinsic value", Nance $(1988,296)$. See also Robertson $(2010$, 182): "Some suppose that the truth has intrinsic value for the legal system, just as it does in the sciences".

8 Steiker $(1997,806)$.

${ }^{9}$ For further discussion of the role of truth in law and adjudication, see Kaplow (1994) 
in achieving whatever it is supposed to achieve - fail to exhaust truth's significance to the law. Even independently of any other goods we may want the law to achieve, it seems plausible to think, it's important that the law not proclaim that $p$, when in fact not- $p$ is the case. At times, for instance, the law seems to have an important setting-the-record-straight kind of function, and when it does, truth seems to matter even independently of other payoffs: Think, for instance, about the importance, even independently of punishment, of not proclaiming someone guilty of sexual harassment unless they are; but also of the importance of not proclaiming the main witness against them as less than fully reliable (unless they are). And perhaps it's important that the law not proclaim falsely even in other cases, and furthermore perhaps this importance cannot be fully captured by instrumental reasoning. We don't want to commit ourselves one way or another on this, but we do want to note that it's at least sometimes plausible that the relation to truth is legally important not merely in instrumental ways. If so, this again renders it unsurprising that truth is at least a part of what evidence law is about.

Some parts of evidence law are easily explainable by this relation to truth. Perhaps, for instance, some types of evidence are excluded as inadmissible because they would tend to render the factfinder too biased, thereby rendering their findings less likely to be true (and, over the long run, less reliable $)^{10}$. Other parts of evidence law do not lend themselves as easily to an explanation in terms of accuracy or conduciveness to truth, so it's a good thing that insisting on truth's role does not amount to insisting that only truth matters to evidence law. For a standard example, think of the doctrines known as "the exclusionary rule" and "fruits of the poisonous tree", according to which (roughly) illegally obtained evidence and its derivatives are inadmissible ${ }^{11}$. The most natural explanation of this doctrine is not in terms of maximizing accuracy at all - after all, illegally obtained evidence may be highly truth-revealing. Rather, in employing this doctrine, the legal system expresses its willingness to pay a price in accuracy (certainly with regard to the case at hand, and maybe more generally too), in order to secure some other important goods (in this case, probably incentivizing the police not to obtain evidence illegally) ${ }^{12}$.

Evidence law may have other purposes too, purposes that are not easily reducible to anything in terms of accuracy or truth. Perhaps, for instance, evidence law joins hands with some parts of procedural law to respect (and protect) some procedural rights, like those of each party to be able to argue

\footnotetext{
10 See, e.g., Guthrie et al. (2001).

11 Mapp v. Ohio, 367 U.S. 643 (1961); Wong Sun v. U.S., 371 U.S. 471 (1963); Miranda v. Arizona, 384 U.S. 436 (1966)

12 The various privileges under common law, such as the public interest privilege, the privilege of spousal communication, or the attorney-client privilege, are also stark examples of the willingness to pay a price in accuracy in order to promote other social goals. They allow the holder of the privilege to refrain from disclosing information in judicial (or other) proceedings, including evidence which could shed light on the factual issues at hand, in order to secure a host of social ends - ranging from marital intimacy to the proper functioning of the state and its institutions.
} 
their case effectively, and perhaps such procedural rights are justified not merely in terms of accuracy $^{13}$. And perhaps evidence law is relevant not just to procedural incentives (such as the incentives for the police not to conduct illegal searches) but also for incentives regarding primary behavior: Sanchirico argues, for instance, that the inadmissibility of character evidence (at the trial stage) serves such a role ${ }^{14}$, and in previous work we've argued for a similar story regarding at least some cases of statistical evidence - routinely relying on statistical evidence may weaken the incentives for primary behavior that the substantive law hopes to secure ${ }^{15}$.

The lesson so far is unsurprising: Truth matters for evidence law; Also, truth is not the only thing that does. The reason we've been emphasizing this familiar point is that it's going to be important to bear it in mind as we proceed. In the next two sections we argue that the law should not intrinsically care about knowledge, or indeed about any other epistemic status. When evaluating this claim it will be important to remember, first, that it does not challenge the obvious point that truth matters, and second, that we're not assuming that only truth should matter for evidence law. Of course other things too matter. The question, though, is what other things should matter. When we accuse some other views of knowledge fetishism, our point is that whatever else except for truth should matter for evidence law, knowledge should not. Indeed, we agree that sometimes evidence law should (and does) strike a balance between accuracy and other important things (like the need to incentivize the police, or to respect some procedural rights, or to give the right incentives for primary behavior). When we criticize knowledge-fetishism we merely insist that accuracy should not be compromised just for that.

\section{Knowledge Fetishism}

An evidence law regime may be designed with the aim - or an aim - of making sure that fact-finders do not find that $\mathrm{p}$ unless they know that $\mathrm{p}$; that an accused is not convicted unless they are known to have committed the crime; that no one is found liable in torts unless they are known to have (probably $\left.{ }^{16}\right)$ committed the relevant wrong; that the law does not proclaim that $p$ unless the relevant legal official (or the state, or the law) knows that p; and so on. That is, an evidence law regime, or a legal system, can assign a positive value to knowledge. In assigning knowledge such positive value, the relevant legal system need not, of course, assign it absolute value. It may be willing to trade off knowledge for other important things, at least some of the time (though the examples above - in line

\footnotetext{
13 For some discussion, see Enoch (2018).

14 Sanchirico (2001).

15 See Enoch, Spectre and Fisher (2012). And for some more details, see Enoch and Fisher (2015).

${ }^{16}$ Right off the bat it's clear, then, that a knowledge-requirement sits much less naturally with weaker burdens of proof compared to that of the criminal law, in terms of "beyond a reasonable doubt". The "probably" qualifier in the text originates with Sarah Moss's (2018a, 2018b) way of applying a knowledge-account also to the standard of proof common in torts, via her claim that credences, just like beliefs, can amount to knowledge. There'll be more of this below.
} 
with the knowledge-accounts offered in legal epistemology ${ }^{17}$ - don't seem to allow such tradeoffs). But if a legal system is to seriously take knowledge to be of value in this way - if it is to treat knowledge as itself of value - it must be willing to pay a price in other things in order to secure knowledge for its findings.

Now, sometimes a conflict will not arise. Perhaps, for instance, knowledge - or a policy of seeking knowledge - will tend to also correlate nicely with accuracy, so that a system that requires its factfinders to base their findings only (or mostly) on what they know will also tend to yield true judgments more often than systems that do not give a pride of place to knowledge. Indeed, perhaps sometimes fact-finders seeking knowledge (rather than merely truth, or truth and justification, or some such) will better facilitate the law's achieving whatever it is that it is meant to achieve. Such a happy coincidence is surely possible, but: First, it is (or would be) a coincidence. Whether or not seeking knowledge maximizes accuracy is a contingent, empirical matter, and there's therefore no guarantee that this is always and necessarily going to be the case. At least for the cases in which it can be shown that going for knowledge does not increase, and indeed has a price in, accuracy, then, the happy coincidence from a few lines ago is no vindication of the legal significance of knowledge. Second, if pursuing knowledge for the system's fact-finders ends up being - in a specific jurisdiction, perhaps in a specific set of circumstances - conducive to accuracy then of course we should pursue knowledge, but then knowledge drops out of the justificatory picture, because then whatever is helpful in securing or facilitating knowledge is ipso facto helpful in securing or facilitating or maximizing accuracy. So everything can be done directly in terms of maximizing accuracy - knowledge is relegated here to, at most, an uninteresting step on the way of the justifier to the justified.

These are somewhat delicate points, and an example may help us make them more clearly. Suppose you're a professor, perhaps even of the kind that teaches real people, in real classes, on real campuses, and not just on Zoom. You have a host of what we can call educational goals in teaching. You want the students to acquire some knowledge, to familiarize themselves with some ways of thinking, to acquire whatever is needed to become a part of certain (oral and written) conversations, to develop their critical thinking, to improve their writing skills, and so on. Suppose the question then comes up whether it's also important that your classes be entertaining. Well, one thing to note is that very often, making the class at least somewhat entertaining is a great means to doing better in terms of your educational goals. A (mildly) entertaining class will tend to keep students more receptive and open-minded and alert, for instance. But the analogues of the two points from the previous paragraph apply: First, this relation between a class being entertaining and it achieving the relevant educational

\footnotetext{
17 For instance, Blome-Tillman (2017), Littlejohn (2020), Moss (2018a, 2018b) as well as Smith (2017, 2018, 2021a, 2021b) who has another epistemological legal proof theory in terms of his normalicy theory of justification (that can and often will depart from accuracy).
} 
goals is contingent - there is no guarantee that ensuring that your class is entertaining is always and everywhere the best way, or even just a good way, of achieving your educational goals. And second, and now restricting ourselves to just the cases in which making your class entertaining does help in achieving the relevant educational goals: In those cases, of course you have a reason to make your class entertaining, but the weight of this reason is fully accounted for by whatever reasons you have to pursue those educational goals. In such a case, then, making your class entertaining is of instrumental value. Furthermore, even those who refuse to think of entertainment as of intrinsic value (when it comes to classes) should agree that in those cases in which this would be instrumental to educational goals, there's at least some reason to make your class entertaining. ${ }^{18}$ If you really care about making your classes entertaining - in a way that is not fully accounted for by your caring about the (other) educational goals - then you must be willing to pay, at least sometimes, at least some price in the hard currency of those other goals, in order to make your classes entertaining. And there need be nothing wrong about having such an attitude - we certainly have that attitude about some other features of teaching. Perhaps, for instance, it's important to make the atmosphere in your classes respectful for all, and perhaps this importance is not exhausted by the way in which ensuring such an atmosphere is likely to facilitate your (other) educational goals, so that you're willing to do a little less well on those educational goals in order to make sure the class atmosphere is respectful for all. It's not clear, though, that we should say the same about making our classes entertaining.

Getting back to legal epistemology: If the controversy when it comes to legal epistemology is whether or not knowledge is intrinsically significant, whether it's significant and worth achieving in a way that is not fully accounted for by its instrumental role vis-à-vis accuracy, then the relevant test is whether we should be willing to pay a price in accuracy in order to achieve knowledge. So consider the following thought experiment ${ }^{19}$ : You are designing the legal system under which your children will live. How many more false convictions are you willing to allow this system to generate, just in order to make sure that the system does better in terms of knowing its findings than some alternative system (that doesn't care about knowledge, but is a bit more accurate, and renders a few less false convictions) $?^{20}$ It seems to us clear - entirely obvious, in fact - that you shouldn't be willing to allow even

\footnotetext{
18 The terms "intrinsic value" and "instrumental value" are used in more than one way, and in some contexts finer distinctions are needed (see Schroeder 2016), but not in others, we think: The distinction we are after - regarding, ultimately, knowledge and other epistemic statuses - is that between claiming that knowledge's legal value or significance are fully accounted for by noting how knowledge promotes or facilitates other legal desiderata, and claiming that knowledge's legal significance is not exhausted in this way.

19 We first offered it in our $(2012,212)$. We discuss knowledge fetishism also in Enoch and Spectre (2021).

${ }^{20}$ We are using here an intuition pump as a part of a normative discussion. We are trying to pump your normative intuition, to express ours, and to see how intuitions feed into (and are molded by) reflection. We are not here putting forward a sociological claim about how "the folk" are likely to respond to the question in the text. For the record, though: if you for
} 
for one more false conviction (and so for some increased chance of your children being falsely convicted) just because of the purported value of knowledge here. Any other policy - any willingness to trade off additional false convictions just for knowledge - will be guilty of what we called knowledgefetishism, and precisely for that reason entirely unacceptable ${ }^{21}$.

Now, you may think that what does the work here is our focus on false convictions. We already know, of course, that the criminal law is asymmetric, and that it treats the risk of false convictions more seriously than the risk of false acquittals ${ }^{22}$. Ok then, how about false acquittals? How many more of those are you willing to incorporate into your designed legal system just in order to make sure that your fact-finders only convict when they know that the defendant is guilty? (And remember to keep all else, including accuracy, constant!). The crucial thing to remember here are the tremendous costs of (true) convictions. The criminal law, even in the system you're designing now for your children's

some reason are interested in this sociological question, it's not going to be easy to conduct the experiment testing it. For one thing, you are going to have to somehow operationalize the fine distinctions between different explanation of specific cases (in terms of knowledge, or in terms of incentives, or in terms of instrumental effects on accuracy, or ...). Perhaps a more promising methodology would be to review relevant entrenched legal doctrines, trying to tease out the relevant folktheory from them. Our own discussion of legal doctrines in the context of discussions of statistical evidence (Enoch and Fisher 2015) does not seem to challenge the intuitions we're pumping in the text here. But we digress. We thank Sarah Moss for relevant discussion.

${ }^{21}$ Another way of seeing the fetishism point is to notice that a knowledge-standard - while clearly a high standard - is not the highest possible epistemic standard. Why not insist on only basing legal decisions, say, on what the fact-finder knows with certainty? Or on what the fact-finder knows that she knows? Legal epistemologists who are knowledge enthusiasts presumably reject such stricter standards, presumably for reasons analogous to those in the text here - achieving knowledgeof-knowledge, for instance, is just not important enough to pay a price in whatever goods the law is supposed to deliver. But now they find themselves in the awkward position of having to explain why paying such a price for knowledge is - while for even higher epistemic standards is not - justified.

22 Sarah Moss $(2018,215)$ emphasizes this point in responding to our initial discussion of knowledge fetishism. A part of her claim here has to do with the factivity of knowledge: Because knowledge is factive, insisting on known-guilt as a necessary condition for conviction is guaranteed not to increase the number of false convictions (as known-guilt entails guilt). Not so, of course, for false acquittals. But the factivity of knowledge is irrelevant here: You are now designing the system. You can include in this design an instruction for fact-finders, say, not to convict unless they know. So they're going to try. But while knowledge is factive, aiming at knowledge is not, of course. The relation between aiming at knowledge on one side and truth on the other is contingent and empirical, not one of entailment. So here as everywhere else, the point from the previous paragraph applies. If aiming at knowledge is instrumental to accuracy, all is well, but the (intrinsic) value of knowledge has not been established. If Moss wants to establish the intrinsic significance of knowledge, she has to be willing to pay a price in accuracy, and as far as anything thus far said is concerned, this price should be paid also in false convictions. Certainly, the factivity of knowledge won't save the day here.

It is perhaps open to Moss to insist - as she does when speaking of a defendants' right to be convicted on nothing less than knowledge - that she endorses a requirement in terms of knowledge, not in terms of aiming at knowledge. Relatedly, she can insist (as she has in correspondence) that she's engaged in the project of finding the norms that apply to fact-finders, not (at this stage) in formulating jury instructions. We don't think this can be plausibly maintained at the level of system design, but we return to something along these lines in discussing the conscientious fact-finder's perspective (there we also return to Moss, engaging her claim that she doesn't engage in the system-design discussion). In Moss (2021b) she responds to a related worry about factivity where she answers in terms of external and internal norms without saying what her view is committed to if her externalisticaly formulated laws - as she rightly says laws often are - increased false convictions (or were too restrictive to make a legal system worth having).

We thank Sarah Moss for relevant discussion. 
society, is bound to create a lot of misery and suffering - every criminal justice system does - and while perhaps the convicted's suffering may be discounted, surely that of their loved ones cannot. It is bound to be very expensive in resources that could have otherwise been used to do a lot of good. If still, with all these consequences in mind, you include a criminal justice system in your designed legal system, this must be because it is extremely important to do so, because that system has sufficiently positive value to outweigh all of these costs. But if so, then false acquittals - even if not as problematic as false convictions - are a very big deal. Perhaps what justifies the horrible costs of a criminal justice system is that it supplies protection for some of our most important interests by deterring the most heinous violent crimes. If so, then, ask yourself: How many more people are you willing to have assaulted, or murdered, or raped under your designed system, just in order to secure the status of knowledge for the findings of your criminal justice system? Similarly for any other value you think is supplied by the criminal justice system - but remember that it has to be sufficiently weighty to justify the horrible costs in terms of suffering and lost resources that that system has. And we submit that any values that may justify having a criminal justice system to begin with will be so important, that the thought of sacrificing some of them just for the sake of knowledge is ridiculously knowledge-fetishistic $^{23}$.

Admittedly, not all non-criminal cases are as intuitively striking as the criminal ones. Some are: How many more mistakes are you willing your system to give rise to when it comes to, say, child custody cases, just in order to insist that the fact-finder know the relevant factual judgments that they are making? With other cases - perhaps some tort cases, where it seems like much of the story is about money, and furthermore, mostly about insurance money - perhaps it's less immediately clear that there is something objectionably fetishistic about paying a price in whatever good the relevant part of the law is supposed to deliver just for the sake of knowledge. Money too, however, is significant, and even in cases that are primarily about money the law achieves important aims, ones it is not at all obvious it's worth giving up on just in order to insist on knowledge. Indeed, once we're careful about holding everything else - primarily, instrumental considerations - constant, and having learned the lesson about the criminal law and perhaps some other parts of the law, it seems to us very plausible that in those cases too, one should not be willing to pay a price in important other goods just in

\footnotetext{
${ }^{23}$ Moss's (2021a) contribution to this volume seems to us like an especially clear example of knowledge fetishism. The thought that the decision on what information should and what should not be disclosed to juries in criminal trials should be guided - solely, no less! - by considerations about the neatest way of specifying the details of a pragmatic encroachment view in epistemology seems to us like its own reductio. Some of the considerations Moss discuss are, of course, relevant to such decisions. But they are all practical, not epistemic. Whether they also turn out to be epistemically relevant (by courtesy of some pragmatic or moral encroachment thesis) drops out of the legal picture entirely.

It is an interesting question - one we cannot pursue here - what a knowledge-based view can achieve if it incorporates also a distinction between acquittals based on knowledge of innocence and those based merely on the absence of knowledge of guilt.
} 
order to humor one's enthusiasm about knowledge. And if you want to insist that knowledge really is intrinsically legally significant, just not when it comes to the criminal law, or custody law, or ... - well, in that case it seems you have yet another explanatory burden you need to shoulder: Why is it that knowledge's value only comes to the fore in the cases in which it purportedly does? ${ }^{24}$

Before proceeding to show - in the next section - that the conclusion about the intrinsic insignificance of knowledge quickly generalizes to any other epistemic concept, there are two complications that we should address here. Both show that we have been overstating our case when we've been saying such things as that unless you're willing to pay a price in accuracy for knowledge, you don't value (intrinsically) knowledge, or that unless you're willing to pay a price in educational goals you don't (intrinsically) value the entertaining value of your class.

First, it doesn't in general follow from an unwillingness to pay with one value for a purported other that the latter is of no value. All that follows is that if the latter is of value, it is always and everywhere lexically inferior to the former. You may, for instance, prefer the more entertaining of two ways of teaching your class so long as the two are equally good when it comes to the relevant educational goals. If so, you do attribute (perhaps intrinsic) value to your class being entertaining - it's just that you never think of this value as sufficiently important to justify paying a price in educational goals. An analogous line is available to someone who wants to insist that evidence law should (intrinsically) care about knowledge, but only when breaking ties, when deciding between two possible evidence law regimes that score equally highly with regard to anything else that's relevant to evidence law. Still, we take it that legal epistemologists who are very much into knowledge want much more than this ${ }^{25}$.

Second, and now restricting our attention to just the friends of knowledge who are willing to pay in other values: We've been writing as if the only currency in which a legal system can pay a price for knowledge is accuracy, or (at the end of the day) truth, and what truth itself helps to achieve. But this is not so. It's possible, for instance, that a legal system can improve its performance in terms of knowledge if, say, it invests more resources in some training for its fact-finders, and without any change in accuracy. If it proceeds along these lines, this will show that it does value knowledge (noninstrumentally, we're assuming), and furthermore, that it doesn't take its value to be lexically inferior to all other values. Still, this too will be a very weak way - though in no way entirely trivial - of assigning

\footnotetext{
${ }^{24}$ Also, for what it's worth: Those putting forward knowledge-based accounts in the current legal epistemology literature tend to focus on examples from criminal law. So it would at the very least be awkward if under argumentative pressure they settle for a weakened thesis with criminal law lying outside its scope.

${ }^{25}$ In the context of discussions of statistical evidence it's very clear, for instance, that proponents of knowledge-accounts think they do much more than merely break ties.

We anticipate the lexical inferiority line already in our "Statistical Evidence, Sensitivity, and the Legal Value of Knowledge" $(2012,213)$.
} 
value to knowledge, and this too seems to be much less than the friends of knowledge in legal epistemology seem to want. On this suggestion, though the value of knowledge may call for a willingness to pay a price in other values, it will never justify paying a price in accuracy. The value of knowledge remains on this picture lexically inferior to that of accuracy. Our arguments here do not directly apply to such a weak version of the legal value of knowledge. We find such a version sufficiently unexciting so that not much is lost here.

\section{Epistemic Fetishism}

The previous section was about knowledge. But the matter is much broader than that. Think of any positive epistemic status that beliefs or judgments or proclamations or procedures may have - something about justification, or warrant, or entitlement, or high probability of knowledge, or epistemic responsibility, or certainty ${ }^{26}$, or any such things. Just in order to make it painfully clear that the details don't matter here, we're going to use the term "The Status" for whatever positive epistemic statuses you want plugged in here. Now we can run the argument from the previous section, and so we can afford to be quick here: How many more false convictions are you willing to allow for, just in order to make sure that your designed system's fact-finder's judgments have The Status? Recall that we're putting the instrumental advantages of having or pursuing The Status, to the extent that there are any, to one side. With this in mind it seems clear that you shouldn't be willing to have your system falsely convict a single additional person purely for achieving more of The Status. Similarly for false acquittals, for the reasons specified about knowledge in the previous section. Similarly for other cases as well. Nothing in the arguments of the previous section relied on anything specific about knowledge compared to any other positive epistemic status. So the arguments run just as before for The Status ${ }^{27}$, whatever its precise details ${ }^{28}$.

What this means, then, is that there is no positive epistemic status for which a legal system should be willing to pay a price in accuracy. No positive epistemic status should intrinsically legally matter.

26 "Certainty" can be understood in several ways, some of which are not epistemic. If this is how you understand certainty, focus on just the other examples in the text.

27 Which means that the argument applies to all the epistemic features included in Pardo's (2010) survey of possible "aims" of legal proof - to the extent, that is, that legal proof can non-metaphorically have an aim at all.

28 Bollinger's (2021) resilience is an interesting case of a status whose nature is not entirely clear. Roughly, a belief is more resilient the less likely it is to be defeated by future evidence. Now, if resilience is understood as an epistemic status, it does seem fetishistic to pay a price in accuracy just in order to secure more resilience for one's legal findings (remember that we're now putting instrumental considerations to one side). But perhaps the case can be made that there are practical reasons - moral, perhaps political ones - that make resilience especially important in the legal case. After all, it does seem plausible to think that a legal system whose findings are defeated too often by later-achieved evidence is worse for this. If so, resilience can be seen as a practical virtue of beliefs, in which case there need be nothing fetishistic about paying a price to secure it.

One general problem for a resilience-based view is that usually sufficiently high probability does translate into lower likelihood of counter-evidence. For some relevant discussion, see Leitgeb (2014). 
The law shouldn't (intrinsically) care about any epistemic status. In this sense, then, legal epistemology rests on a mistake.

Perhaps it's worth addressing here a possible objection (for which we thank Matt Kotzen), one also based on thoughts about generalizing our claim, only in a different direction. Don't our arguments equally show - if they succeed at showing that knowledge, or The Status, do not intrinsically matter to the law - that they don't matter to anything else as well? In particular, don't they equally show that epistemology doesn't matter to ethics? And isn't this an unacceptable result, seeing that we often do invoke epistemic concepts in commonsense ethics (as when we insist, say, that only those who know they are safe drivers can permissibly drive, and that if you knew that he was so sensitive, you shouldn't have used that tone of voice)? Our arguments do not immediately commit us to this result - recall that we relied on the importance of the costs (via legal accuracy) paid by insisting on attributing intrinsic value to The Status. Whether this applies to other domains (including all of ethics) remains to be seen. And of course, epistemology may (intrinsically) matter for ethics in other ways, not by directly entailing any practical conclusions - for instance, blameworthiness may be undercut by relevant ignorance. But if the suggestion is that ethics is sensitive to the niceties of epistemological discussions of conditions for knowledge and justification and so on - then we are happy to accept the generalization (as we do in Enoch and Spectre (2021)). Nothing of practical ethical significance should be intrinsically sensitive to such epistemic considerations, and we suspect that indeed, nothing in our commonsensical moral discourse is. (Just think about what responses are - and what aren't - appropriate to an accusation in terms of "You knew he was so sensitive now!". No epistemic niceties will do, of course.)

\section{Remaining Discomfort}

You may be less than fully satisfied. After all, if evidence law shouldn't - and doesn't - care about epistemic status, then why does it often seem that it does?

We've already noted the fact that the law seems to be using natural-language epistemic terms. But there's more. For instance, if you say, of a judge or a jury-member, "She voted to convict without knowing the guy is guilty", it's very hard to read this as anything but criticism; indeed, it's very natural to add a "but" or similar locutions to this sentence, resulting in something like "She voted to convict, even though she did not know the guy was guilty", or "They voted to convict despite not knowing that the guy is guilty", and all of this linguistic data seems to indicate an expectation to only convict when one knows the guy is guilty. First-person statements give rise to a similar impression: Without some special story, "I'm not sure he did it, but we should convict" or "We don't know he did it, but we should convict" (and certainly the same sentences with "and" instead of "but") sound terribly awkward, perhaps borderline paradoxical. 
Now, such linguistic evidence - though always relevant - is rarely if ever conclusive, and alternative explanations, ones that do not assign legal value to knowledge, may be thought of. Perhaps, for instance, third-person cases can be explained as parasitic on first-person cases, and perhaps first-person cases can be explained (without attributing any legal value to knowledge) by referring to the (purported) knowledge norm of assertion ${ }^{29}$, together with the auxiliary premise that by asserting that a conviction is called for one is also asserting that the defendant is guilty (an assertion that is only in place if one knows that this is so). In the opposite direction, in order to assert that one doesn't know that $p$, one needs to know that one doesn't know that $p$, and this requires (at least typically) either evidence for not- $p$, or undercutters for the evidence one had for $p$, and in either case the conviction - based on one's belief that $p$ - is thereby criticizable, independently of any knowledge requirement. Or perhaps we can rely here on Grice' $s^{30}$ maxim of quantity, according to which one should make one's contribution to a conversation maximally informative (or as informative as the context requires): According to it, when we say in typical contexts "She didn't know the guy was guilty", we imply that she didn't have sufficient evidence either (otherwise, we would have conveyed the information about her having such evidence). And if she didn't have sufficient evidence, this of course suffices for justifying the criticism, independently of a knowledge condition.

Also, if we're playing the linguistic game, we should play it holistically, both in terms of considering more contexts, and in terms of other linguistic data. For other contexts, consider that there are contexts in which an utterance of "They voted to convict without knowing the guy was guilty" need not be understood as a criticism. Perhaps, for instance, it is well known in the relevant context that the evidence presented to the jury easily passed the BARD threshold, but was nonetheless misleading. In such a context, it may be asserted that the jury members really did all they could - in fact, they would have been in violation of their duties had they not convicted. Still, they didn't know the defendant was guilty (because he wasn't, and knowledge is factive). So we need to leave room for attributions of knowledge-failure not to be instances of criticism - and it's hard to see how this can be done while insisting on a knowledge condition.

As for other linguistic data, some of it seems to point in other directions. Think, for instance, about a conscientious juror who voted to convict, based on a good-faith evaluation of the evidence available to them at trial, and suppose that later on our juror finds out - by way of new evidence that was not available at the time - that the person was innocent. Suppose he then says something like "I did what I could. The evidence we were shown was strong beyond a reasonable doubt. Still, it turns out I was wrong." This sounds to us a perfectly reasonable thing to say. But of course, this seems to indicate

\footnotetext{
29 Williamson (1996, 2000), DeRose (2002), Adler (2002), and Reynolds (2002) are early prominent proponents of the knowledge norm of assertion.

30 Grice (1989).
} 
that the BARD standard is not factive, whereas knowledge is. So this piece of linguistic evidence counts against thinking of knowledge as relevant here ${ }^{31}$.

Perhaps all such linguistic evidence should be taken with a pinch of salt. The following seems more serious of a challenge to the claim that epistemology shouldn't matter to the law of evidence. Pardo (2010) draws attention ${ }^{32}$ to cases in which the fact-finder's judgment is Gettierized. That is, cases in which the fact-finder's judgment is true, and indeed justified, and yet intuitively does not amount to knowledge. Here is the case Pardo $(2010,50)$ calls "Framed Defendant":

The police arrest a motorist and plant drugs in his car. He is convicted at trial of illegal possession based solely on testimony from the arresting officers and the planted drugs. As it turns out, the defendant did have illegal drugs in his car at the time that never were discovered. The verdict that the defendant possessed drugs is therefore both true and justified...

It's not clear to us what exactly to say of this case, but we want to agree with Pardo that at the very least this is not a paradigmatically successful conviction. One explanation of the problematic nature of this conviction - the explanation Pardo seems to go for - is that in such a case the judgment that the defendant is guilty of illegal possession is, though true and justified, not known (because Getterized), and that justified conviction requires knowledge ${ }^{33}$. This kind of inference to the best explanation is not conclusive - again, alternative explanations may be thought of and need to be evaluated to determine which explanation is best ${ }^{34}$ - but this line of thought does seem to run deeper than the

${ }^{31}$ Although things are tricky here. "She proved it" sounds factive. So you may think that "She proved it beyond a reasonable doubt" is also factive. Then again, you may think that the "beyond a reasonable doubt" in "she proved it beyond a reasonable doubt" functions as a qualifier (perhaps like "She proved it according to the standards then in place") rendering the whole expression ("She proved it beyond a reasonable doubt") non-factive. Indeed, "She proved his guilt beyond a reasonable doubt. Shockingly, it then turned out he wasn't guilty." doesn't sound as paradoxical as "She knew he was guilty. Shockingly, it then turned out he wasn't guilty."

32 Pardo also refers to others who have used similar cases to similar effect. See especially his reference to Duff et al (42, footnote 20), and references in footnote 44 (47).

33 Framed Defendant is a more realistic example than some of the others Pardo uses, but - perhaps because of this - it's also less clean. First, a cleaner example would involve no police misconduct, because such misconduct may give rise to a reason to acquit independently of the considerations (like the role of knowledge) that the example is supposed to highlight. Second, perhaps the conviction should be seen not as a conviction for possessing that-much of drug so-and-so, but rather for possessing that-specific-batch of the drug (the one entered in evidence). If so, the judgment on which the conviction is based is not Gettierized - it is plainly false, and different issues come up - like the problem of specification (see, for instance, Schauer (MS).). For argument's sake we take onboard (pretty much uncritically) the possibility of somewhat fancier Gettier cases that are largely immune to the worries in this footnote. One of us (L.S.) is skeptical that there are such possible cases that do not equivocate legal and epistemic justification.

${ }^{34}$ For instance, perhaps what explains the problematic nature of the conviction in Framed Defendant is not the absence of knowledge, but whatever it is that explains why knowledge is absent. If this is so, again knowledge drops out of the picture.

Such an explanation - if the details can be filled in in plausible way - is structurally similar to the explanation we put forward in our (2012) for the problematic nature of statistical evidence: The counterfactual Sensitivity, we argued, is epistemically relevant. But what explains the suspicion regarding statistical evidence are not the epistemic problems Insensitivity 
linguistic evidence from the previous paragraph.

As a last - to us, the most important - indication of remaining discomfort with the claim that no epistemic statuses are intrinsically significant to the law, consider the phenomenology of fact-finding. Many years ago, in a discussion of statistical evidence, Aharon Barak ${ }^{35}$ made the following point:

I understand, of course, that any legal system is bound to make mistakes, and I understand how probabilities work. Still, when judging, it's not about probabilities at all. I seek certainty. I think of the different burdens of proof and different statistical requirements - say, requiring over $90 \%$ - as mere instruments with which I can convince myself - with $100 \%$ certainty - that the defendant is guilty. If all I am convinced of is that there's a $90 \%$ chance that the defendant is guilty, then I will acquit. (Similarly for other probabilistic thresholds.)

This is not, as it stands, a statement about knowledge, or any other epistemic status (with the possible exception of certaint $\left.{ }^{36}\right)$. But it seems to go rather well with a knowledge-account, and anyway, this line of thought seems to resist the kind of considerations we've been making much of, about which tradeoffs one is willing to make as between accuracy and securing for one's findings some important epistemic status. And it is not hard to imagine someone conveying a similar sentiment with something like: "Oh, you can go ahead and do your theory if you want. But myself - unless I know they did it, I don't convict". ${ }^{37}$

There seems to be something deep and important about this - it seems to capture something important about what it is like to convict (or refuse to convict). Furthermore, there need be nothing objectionable about the attitude expressed with "unless I know they did it, I don't convict" - indeed, perhaps there is something objectionable about not manifesting such an attitude. All of this does seem to be in tension with (even if it doesn't contradict) the conclusion of previous sections, namely, that

gives rise to, but rather the Sensitivity-counterfactuals which explain the epistemic problems, and which themselves can be shown to be practically relevant.

35 We do not remember the precise wording. But Chief Justice Barak has recently confirmed, in email correspondence, that what we say here does reflect his way of thinking about things.

It is perhaps worth noting that in the Israeli legal system there are (usually) no juries, and so that judges are also the factfinders.

${ }^{36}$ Which - to repeat a point from an earlier footnote - can be understood in different ways, some of which more epistemic than others. That there is nevertheless $a$ sense in which certainty seems closely analogous in our context to knowledge can be seen from the fact that the intuitive force of Barak's thought - roughly, "Not certain? Don't convict?" - is preserved when we put things in terms of knowledge: "Don't know? Don't convict!"

37 In what is considered a canonical article in evidence law scholarship, Laurence Tribe (1971) makes a similar claim. He requires judges and jurors to adopt such a state of mind - to seek certainties rather than probabilities, to know of, rather than merely acknowledge the probability (however high) of, the defendant's guilt as a pre-condition for convicting the defendant.

Notice that taking this thought at face value is inconsistent also with Blome-Tillman's (2017) account in terms of the probability of knowledge. 
knowledge (and other epistemic statuses) should not matter when it comes to evidence law. So an attempt at a reconciliation may be called for.

\section{An Attempt at Reconciliation: The Evidence Law Regime and the Conscientious Fact-}

$\underline{\text { Finder }}$

A striking fact about Barak's description of the phenomenology is that it is precisely that - it is a firstpersonal account of the deliberation of a conscientious fact-finder. But the discussion of epistemic fetishism earlier on was all about designing a legal system and an evidence law regime. Perhaps the way forward with our reconciliation effort, then, is to distinguish these two perspectives more clearly and explicitly.

Recall Rawls's early defense of rule-utilitarianism in "Two Concepts of Rules" (1955). Central to that defense is Rawls's suggestion that rule utilitarianism be understood as distinguishing between what justifies a practice - namely, the Principle of Utility - and what justifies specific actions within that practice - namely, the rules that constitute or define the practice. The system, or the practice, is justified in one - utilitarian - way, but the agents acting within it are not expected to deliberate in terms of maximizing utility. In fact, they are positively expected not to do so $^{38}$. Rawls (25) gives examples from games ${ }^{39}$. It's quite plausible to think that when we're designing the rules of baseball, we should take into account such considerations as maximizing the role of athletic achievement (of a specific kind), the crowd's enjoyment, sales, TV ratings, and so on. But the umpire calling balls and strikes at home plate - he should not be thinking in those terms at all. Rather, he should be "calling them as he sees them". In fact, the ability of the game as a whole to supply the goods it is meant to supply (say, in terms of a fun pastime, of some athletic achievement, etc.) partly depends on umpires not thinking in those terms at all.

A similar line of thought can be applied to the law, and indeed, Rawls does apply it to the law, and in particular, to criminal punishment (4-13). Consequentialist considerations - say, in terms of deterrence - do have a role to play in justifying criminal punishment, argues Rawls. But they should not be considered by judges, juries, and courts. Rather, they have a role in designing the system as a whole. Those playing a role within that system should think exclusively or almost exclusively in terms of retribution. In fact, at least to an extent, the possibility of the criminal punishment system to supply

\footnotetext{
38 This is just one of the central points in Rawls (1955), and the only one we're relying on. In particular, we don't claim about any of the rules that we discuss that they play a role in constituting or defining a relevant practice.

39 We are here drawing on Rawls rather freely. Rawls is more interested in the moves within the game - stealing a base, striking out - than in the decisions of the umpires.
} 
whatever goods it is meant to supply depends on judges not deliberating with them in mind ${ }^{40}$.

The crucial thing for our purposes is not whether Rawls succeeds in defending some kind of indirect consequentialism, or how plausible what he says about criminal punishment is. What is crucial for us is the normative structure he focuses attention on, about whose possibility he is surely right. That is, there may be systems that are justified by one set of considerations, but such that agents within the system are required to act and deliberate on other considerations entirely, and indeed are required not to act and deliberate on the considerations that justify the system as a whole. And as we're sure by now you've realized, it is this structure that we want to apply, at least provisionally, to legal epistemology.

Perhaps, then, the arguments against knowledge- and more generally epistemic fetishism apply at the level of designing the system. At that level we should not be willing to sacrifice accuracy (or the other goods truth can help to achieve) just for some epistemic goods, knowledge included ${ }^{41}$. But - this is where Rawls comes in - from this it just doesn't follow that conscientious fact-finders should also think in those system-design ways. Perhaps they should call the facts as they see them, so to speak, ignoring more general considerations of this kind. Indeed, perhaps they should even focus on some epistemic status - knowledge, perhaps, or The Status - refusing to convict (or maybe make other decisions as well) unless they know the relevant facts, or are certain about them, or have sufficient evidence for them ${ }^{42}$.

The advantages of such a story should at this point be clear enough ${ }^{43}$ : It fully accommodates the anti-fetishism point (no tradeoffs of accuracy for The Status), while at the same time taking seriously the remaining discomfort with that point, and most importantly, the point about the phenomenology

\footnotetext{
40 Rawls thinks that a system where judges mete out punishment according to consequentialist (or teleological) rather than retributivist considerations does not even merit being called a system of punishment - he suggests the term "telishment" (11) for it, and insists that a criminal telishment system is inferior to a criminal punishment one even in utilitarian terms.

41 Pardo $(2010,46)$ - despite tying legal proof with epistemology much more closely than we do - seems sympathetic: "a further point of clarification concerns a distinction between systemic and case-specific epistemic considerations. From a systemic perspective, the key epistemic consideration is the total number (and types) of material errors."

42 In comments on an earlier version of this paper, Moss insisted that in terms of a two-tier system of the kind described in the text, she never discusses the legal-design system, but only that of fact-finders. It's not clear to us how this can be reconciled with much of Moss's relevant work (including her contribution to this volume, where the question addressed seems to be what information should be disclosed to the fact-finders - a paradigmatic system-design question), or with the work of many other legal epistemologists. More importantly - as we proceed to note in the text, on our view it's possible that factfinders should care about epistemology, but whether this is so should be justified ultimately in non-epistemic terms (at the level of system design). This, of course, is a claim Moss rejects even on this surprising description of her view.

${ }^{43}$ Ross (2021) emphasizes (against knowledge-based and other epistemic accounts of statistical evidence) that there's no reason to think the same considerations that apply to individuals also apply to courts or juries. This is not our distinction between two tiers, but like ours, it emphasizes the significance of the role of the fact-finder. If Ross is right, though, knowledge shouldn't guide even the conscientious fact-finder.
} 
of the conscientious fact-finder. The implications of such a story to Pardo's Gettier cases seem especially worth-noting: At the level of system design, we stand our ground against fetishism, not willing to tradeoff accuracy - not even very little accuracy - just in order to ensure our system's fact-finders' judgments are not Gettierized. From the first-person perspective of a deliberating fact-finder, though, the Gettier problem disappears (we're talking here, of course, of Gettier cases where there's no evidence indicating that one is likely to be in a Gettier case). All one can do, when presented with the evidence, is to aim at truth, be as responsive to the evidence as one should, and hope for the best ${ }^{44}$. It's not as if there's any anti-Gettier move that is available to the fact-finder ${ }^{45}$. So the question of tradeoffs with accuracy, from that perspective, doesn't even arise - it's not something the fact-finder should worry about at all. We take it this is a satisfying result.

The advantages of this two-tier story, then, are clear. But we want to note, before concluding this section, two of its liabilities, and one further implication. First, recall that in the case of the Rawlsian story about baseball, it wasn't enough to note the possibility of the two-tier structure. The plausibility of that structure also depends on the details, and in particular, on there being reasons to believe that if we collapse the two tiers - if umpires start deliberating in terms of athletic achievement, and TV ratings, and so on, and not just in the highly constrained terms of balls and strikes - something of value will be lost, indeed, that if we collapse the two tiers this will tend to defeat precisely the goods baseball is supposed to supply. (Similarly for the case of criminal punishment, if Rawls is right about it.) For our two-tier story to be equally plausible, then, reasons must be given to believe that if factfinders think in the terms that are fitting for the system's design (refusing to trade off accuracy for any epistemic status) something of value will be lost. Perhaps such a story can be told - say, in terms of the integrity of the fact-finders ${ }^{46}$, or public trust in them and in the system of which they are a part ${ }^{47}$. Our point here, though, is that some such story must be told to complete the two-tier account we're considering in this section.

Second, for a two-tier account to be complete, it must also be shown that the "acoustic separation $^{\prime 48}$ between the two tiers can be maintained. In baseball, this is easy enough. We don't know to

${ }^{44}$ Typically, the fact-finder is not even in a position to require that more resources be put into collecting evidence.

45 We cannot here engage the more general discussion of what epistemic constraints, if any, have to be accessible from the first-person perspective. Arguably, no anti-Gettier clause is accessible from the first-person perspective, and - if you reject KK - neither is any knowledge requirement.

46 Perhaps Whitman's (2008) historical account - according to which the BARD rule was developed with an eye not to protecting the interests of the defendant but rather the integrity of the jurors - can support such a thought.

47 According to Nesson (1985), judges must strive not for the probable or most accurate verdict but, rather, for the publicly accepted or trusted one. The goal of generating rulings that the public will accept and trust cannot be reached simply by resorting to those that are most probably accurate. While accurate and acceptable verdicts may often coincide (since attempting to unravel the truth is one way to facilitate public trust) this is not always the case. As in the instance of statistical evidence, claims Nesson, an accurate decision may not necessarily be publicly acceptable, and vice versa.

48 Meir Dan-Cohen (1984) made this term famous in a different context. We're freely using it here. 
what extent umpires would be inclined to consider other considerations, but anyway, they are clearly instructed to restrict themselves to the very limited considerations that are relevant at their level. So maintaining the separation between the two tiers is entirely feasible. Can a similar story be told when it comes to evidence law? Things are tricky here. If conscientious fact-finders are supposed to go with the knowledge rule for criminal conviction ${ }^{49}$ (“Don't know? Don't convict!"), it is tempting to include an instruction to this effect as a part of the system-design. But then, either the two tiers collapse into one, or else we find ourselves advocating a non-transparent system that pretends to care about knowledge (by including such an instruction to its fact-finders) while in fact attributing no value to knowledge. It's possible that such non-transparency is indeed called for, but this is a less than fully welcome result. So if the two-tier story can be made to work without restricting access to the considerations relevant to system design only to some privileged insiders, the mechanisms in place will have to be more complicated. For instance, admissibility rules can play a central role here. If some types of evidence are pronounced inadmissible for system-design reasons, and so are not made available to the fact-finder, we can then make reasonably sure that the fact finder restricts her deliberation to just the admissible evidence (much like the baseball umpire restricts his deliberation to considering the location of the ball relative to the strike zone). In such cases, then, perhaps the two-tier structure can be maintained. Of course, if this is the only kind of case in which the two-tier structure is stable, an interesting conclusion follows: When it comes to considerations of admissibility, we should avoid epistemic fetishism, and focus on accuracy (and incentivizing the police, etc.). And this means that nothing about knowledge can explain anything about admissibility. This has powerful implications to more specific debates, that we cannot get into here ${ }^{50}$.

Lastly, it is natural to seek similar-structured two-tier stories elsewhere in the law. If more cases can be found where a plausible two-tier story can be told, this will render the story told here more plausible (because less ad-hoc). And it doesn't seem like the Rawlsian intuition we've been working with in this section is at all restricted - it should apply across legal domains, and indeed more widely still to other institutional setups and other practices (this, after all, was Rawls's point - for him the law was just an example, rendered prominent because of common objections to utilitarianism that he was interested in responding to). And we do think that such two-tier stories are very plausible with regard

\footnotetext{
${ }^{49} \mathrm{We}$ 're focusing here on the criminal law. A full discussion will of course have to accommodate the rest of the law as well.

50 Let us just hint at one. In the context of the discussion of statistical evidence, some writers invoke the knowledge account to explain the way in which statistical evidence is problematic. We are committed to this being the wrong story to tell, to a large extent because of the problem of knowledge fetishism. If the point sketched in the text here is correct, though, then nothing about a knowledge-account can explain anything about admissibility, as admissibility works at the system level, where we shouldn't care about knowledge. To the extent that the problem with statistical evidence goes through to issues of inadmissibility, then, the knowledge-account is not the way to go, and this even if the reconciliation project of this section goes through.
} 
to a wide range of legal and other social arrangements. Here are several examples - though, of course, much more needs to be said about each in order to establish the two-tier understanding as the best one regarding them:

(i) In civil law - for instance, in torts - judges are restricted to ruling according to the merits of the case brought before them, and are ordinarily banned from taking wealth or power disparities between the litigating parties into account in their verdicts and in the awarding of damages. Such considerations, however, are arguably incorporated at the systemic level, and constitute an important factor of institutional design. One can think of small claims courts, with their flexible procedural regime and limited costs of trial, as a means of addressing and mitigating wealth disparities between litigants. The same holds true for the institution of legal aid.

(ii) While the criminal justice system is governed by the BARD threshold at the conviction phase of the trial, in a way that insulates it from the sentencing stage, still it may be argued that decision-makers within the system are implicitly instructed to adjust levels of certainty for a conviction to the expected sanction and that residual doubt continues to be a mitigating factor in punishment ${ }^{51}$.

(iii) Perhaps while it is extremely important - at the level of system-design - to take into account considerations about the public's trust in the legal system, still for decision-makers within the system - a fact-finder in a specific trial, for instance - to take such considerations into account would be a serious violation.

(iv) For a not-exactly legal example, and indeed a normative one - that is, one where we don't argue that a two-tier story explains existing arrangements, but may be a good idea for a (moderate) reform - consider affirmative action programs in (e.g.) academia. Various policies are implemented with the objective of promoting substantive equality and diversity on campus, while maintaining academic excellence. A two-tier system design may prove quite successful in accommodating both ends simultaneously. According to such a system, the selection process in the first tier is procedurally designed to ensure that a high percentage of the candidates brought forth before the committee are (for instance) female. While the initial composition of the list of candidates is comprised in a gender-sensitive manner, the decision-making process underlying the second tier of the system is insulated - at least to an extent - from such considerations. Committee members choosing from among the list of candidates are instructed to act in a manner more

${ }^{51}$ For discussion along these lines, see Lillquist (2002) and Fisher (2012). 
closely resembling gender-blindness, and are restricted to considerations of academic merit in their selection process.

As already noted, it's important not to be too quick about these cases - for each purported case of a two-tier story, alternative accounts should be considered. Even without the needed detailed discussion of each case (purportedly) of this kind, though, we hope it's plausible to think that there need be nothing ad hoc about invoking a two-tier story in our context.

\section{Conclusion}

The picture that emerges, then, is complicated. Of everything we've said, the point we're most confident in is that accuracy should never be compromised just in order to satisfy our epistemic palate. The main advantage of the two-tier view from the previous section is that it may allow - consistently with the rejection of epistemic fetishism at the system level - some room for commonsensical epistemic judgments at the level of the individual fact-finder. If the details can be filled in in a plausible way, it remains true that evidence law shouldn't care about knowledge (and the like), but conscientious factfinders may.

Does, then, legal epistemology rest on a mistake? Those parts of it that suggest fetishistic tradeoffs at the system level (perhaps partly because failing to distinguish between the two tiers) are indeed guilty of a central error. Others need not be - either because they are doing other things entirely (as noted in the introduction, many things fall under "legal epistemology"), or perhaps if they allow epistemic values intrinsic legal significance only when it comes to the level of the conscientious fact-finder, while continuing to stand strong against epistemic fetishism at the system level. 


\section{$\underline{\text { References }}$}

Adler, J. (2002). Belief's own ethics. Cambridge: MIT Press.

Allen, R. (2021). Naturalized epistemology and the law of evidence revisited. Quaestio Facti. 2, 253284.

Backes, M. (2020). Epistemology and the law: why there is no epistemic mileage in legal cases. Philosophical Studies, 177, 2759-2778.

Blome-Tillmann, M. (2017). 'More likely than not' - Knowledge First and the role of statistical evidence in courts of law. In C. Adam, G. Emma \& B. Jarvis (Eds.), Knowledge First - Approaches in Epistemology and Mind (pp. 278-292). Oxford: Oxford University Press.

- - (2015). Sensitivity, causality, and statistical evidence in courts of law. Thought, 4, 102-12.

Bolinger, R. (2021). Explaining the justificatory asymmetry between statistical \& individualized evidence. In Z. Hoskins \& J. Robson (Eds.), Truth and Trials: Dilemmas at the Intersection of Epistemology and Philosophy of Law. University of Nottingham.

Cohen, L. (1977). The Probable and the Provable. Aldershot: Gregg Revivals.

Dan-Cohen, M. (1984). Decisions Rules and Conduct Rules: On Acoustic Separation in Criminal Law. Harvard Law review 97, 625-677.

DeRose, K. (2002). Assertion, knowledge and context. The Philosophical Review, 111, 167-203.

Enoch, D. (2018). In defense of procedural rights (or anyway, procedural duties): a response to Wellman. Legal Theory, 24, 40-49.

- - (2013). Comment on Yaffe's Attempts. The Jerusalem Review of Legal Studies, 6, 20-35.

Enoch, D. \& Fisher, T. (2015). Sense and Sensitivity: Epistemic and Instrumental Approaches to Statistical Evidence. The Stanford Law Review, 67, 557-611.

Enoch, D. \& Spectre, L. (2021). Statistical resentment, or: What's wrong with acting, blaming, and believing on the basis of statistics alone. Synthese. Advanced online publication. doi: $\underline{10.1007 / s 11229-021-03042-6}$

Enoch, D., Spectre, L., \& Fisher, T. (2012). Statistical evidence, sensitivity, and the legal value of knowledge. Philosophy \& Public Affairs, 40(3), 197-224.

Fisher, T. (2011). Conviction without conviction. Minn. L. Rev., 96, 833. 
Gardiner, G. (2020). Relevance and risk: How the relevant alternatives framework models the epistemology of risk. Synthese. Advanced online publication. doi: 10.1007/s11229-020-02668-2

- - (2019a). Legal epistemology. In Pritchard, D. (Ed.), Oxford bibliographies: Philosophy. Oxford: Oxford University Press.

- - (2019b). The reasonable and the relevant: Legal standards of proof. Philosophy \& Public Affairs, 47, 288-318.

- - (2018). Legal burdens of proof and statistical evidence. In Coady, D. \& Chase, J. (Eds.), The Routledge handbook of applied epistemology. London: Routledge.

Grice, P. H. (1989). Studies in the ways of words. Cambridge, Mass.: Harvard University Press.

Guthrie, C., Rachlinski, J. J., \& Wistrich, A. J. (2000). Inside the judicial mind. Cornell L. Rev., 86, 777.

Hoskins, Z., \& Robson, J. (2021). The Social Epistemology of Legal Trials. Routledge.

Kaplow, L. (1994). The value of accuracy in adjudication: An economic analysis. The Journal of Legal Studies, 23(S1), 307-401.

Laudan, L. (2006). Truth, error, and criminal law: an essay in legal epistemology. Cambridge: Cambridge University Press.

Leitgeb, H. (2014). The stability theory of belief. The Philosophical Review, 123(2), 131-171.

Lillquist, E. (2002). Recasting reasonable doubt: Decision theory and the virtues of variability. UC Davis L. Rev., 36, 85 .

Littlejohn, C. (2017). Truth, knowledge, and the standard of proof in criminal law. Synthese, 1-34.

Moss, S. (2021a). Pragmatic Encroachment and Legal Proof. Philosophical Issues: Law and Epistemology. (This volume.)

- - (2021b). Knowledge and legal proof. Oxford Studies in Epistemology, 7.

_ - (2018a). Probabilistic knowledge. Oxford: Oxford University Press.

- - (2018b). Moral encroachment. The Proceedings of the Aristotelian Society, 118, 177-205.

Nance, D. A. (1987). The best evidence principle. lowa L. Rev., 73, 227.

Nesson, C. (1985). The Evidence or the Event? On Judicial Proof and the Acceptability of Verdicts'. Harv. L. Rev., 98, 1357.

Pritchard, D. (2018). Legal risk, legal evidence and the arithmetic of criminal justice. Jurisprudence, 9(1), 108-119. 
Rawls, J. (1955). Two concepts of rules. The philosophical review, 64(1), 3-32.

Reynolds, S. L. (2002). Testimony, knowledge, and epistemic goals. Philosophical Studies, 110(2), 139161.

Robertson, C. T. (2010). Blind expertise. NYUL Rev., 85, 174.

Ross, L. (2021). Rehabilitating statistical evidence. Philosophy and Phenomenological Research, 102(1), 3-23.

- - (2020). Recent work on the proof paradox. Philosophy Compass, 15(6), e12667.

Pardo, M. S. (2019). The paradoxes of legal proof: A critical guide. BUL Rev., 99, 233.

- - (2018). Safety vs. sensitivity: Possible worlds and the law of evidence. Legal Theory, 24(1), 5075.

- - (2010). The gettier problem and legal proof. LEG, 16, 37.

Thomson, J. J. (1986). Liability and individualized evidence. Law \& Contemp. Probs., 49, 199.

Sanchirico, C. W. (2001). Character evidence and the object of trial. Colum. L. Rev., 101, 1227.

Schauer, F. (MS). Statistical evidence and the problem of specification.

Schroeder, M. (2016). Value theory. In E. N. Zalta (Ed.), The Stanford Encyclopedia of Philosophy. url: https://plato.stanford.edu/entries/value-theory/

Smith, M. (2021a). More on Normic support and the criminal standard of proof. Mind. doi: 10.1093/mind/fzab005

- - (2021b). Against Legal Probabilism 1. In The Social Epistemology of Legal Trials (pp. 92-105). Routledge.

- - (2018). When does evidence suffice for conviction?. Mind, 127(508), 1193-1218.

- - (2017). Between probability and certainty: What justifies belief. Oxford University Press.

Steiker, C. S. (1997). Punishment and procedure: punishment theory and the criminal-civil procedural divide. Ann. Rev. Crim. Proc., 26, 775.

Stein, A. (2018). Law and the Epistemology of Disagreements. Wash. UL Rev., 96, 51.

Tribe, L. H. (1971). Trial by mathematics: Precision and ritual in the legal process. Harvard law review, 1329-1393.

Twining, W. (1984). Evidence and Legal Theory 1. The Modern Law Review, 47(3), 261-283. 
Whitman, J. Q. (2008). The Origins of Reasonable Doubt: Theological Roots of the Criminal Trial. Yale University Press.

Williamson, T. (1996). Knowing and asserting. The Philosophical Review, 105, 489-523.

- - (2000). Knowledge and its limits. Oxford: Oxford University Press. 